\title{
EMMA - THE WORLD'S FIRST NON-SCALING FFAG
}

\author{
R. Edgecock, D. Kelliher, S. Machida, STFC/RAL, Didcot, UK \\ C. Beard, N. Bliss, J. Clarke, C. Hill, S. Jamison, A. Kalinin, K. Marinov, N. Marks, B. Martlew, \\ P. McIntosh, B. Muratori, H. Owen, Y. Saveliev, B. Shepherd, R. Smith, S. Smith, S. Tzenov, \\ C. White, E. Wooldridge, STFC/DL, Daresbury, UK \\ J.S. Berg, D. Trbojevic, BNL, Upton, New York, USA \\ M. Craddock, S. Koscielniak, TRIUMF, Vancouver, Canada \\ J. Crisp, C. Johnstone, FNAL, Illinois, USA \\ Y. Giboudot, Brunel University, UK \\ E. Keil, CERN, Geneva, Switzerland \\ F. Méot, CEA \& IN2P3, LPSC, France \\ T. Yokoi, Oxford University, UK
}

\begin{abstract}
EMMA - the Electron Model of Many Applications is to be built at the STFC Daresbury Laboratory in the UK and will be the first non-scaling FFAG ever constructed. EMMA will be used to demonstrate the principle of this type of accelerator and study its features in detail. The design of the machine and its hardware components are now far advanced and construction is due for completion in Autumn 2009.
\end{abstract}

\section{INTRODUCTION}

Non-scaling FFAGs (NS-FFAGs) were invented at the end of the last decade [1], principally for the acceleration of muons in a Neutrino Factory [2]. They are ideal for this purpose as the fixed field nature allows rapid acceleration. Further, the non-scaling nature allows the manipulation of the particle orbits to produce a parabolic variation of the orbit length with energy. This gives a much smaller momentum compaction and hence a smaller orbit excursion than for a scaling FFAG, for example. A remarkable feature of these machines is that this small orbit excursion can be achieved with linear magnetic fields. This gives them a large dynamic aperture and the ability to use higher rf frequencies than scaling FFAGs. In addition, it is possible to accelerate relativistic particles over a factor of more than 2 in momentum without changing the RF frequency (so-called asynchronous or serpentine acceleration [3]), making $\mathrm{CW}$ operation possible for muon acceleration. For these reasons, NSFFAGs have been selected as part of the baseline acceleration system for a Neutrino Factory.

More recently, due to their interesting properties, NSFFAGs have been studied for other applications, in particular a high power proton driver for a Neutrino Factory [4], for proton and carbon cancer therapy [5] and for driving sub-critical nuclear reactors using thorium as a fuel.

However, nothing comes for free and this type of machine also has three unique and potentially problematic features
- Due to the non-scaling nature, the tunes vary over a large range during acceleration. This means many resonances are crossed.

- The very small momentum compaction.

- Asynchronous acceleration has never been intentionally employed by any accelerator.

These features have been studied in some detail for muon acceleration and none appear to prevent NS-FFAGs from working. However, before a machine can be built for this or any other application, it is essential to build at least one proof-of-principle NS-FFAG to study these and all other features of this type of machine. This is the purpose of EMMA.

\section{EMMA}

\section{Aims}

The principal aim of EMMA is to demonstrate that nonscaling optics work, to make a detailed study of the features of this type of machine and to benchmark the codes being used for machine design. In particular, a detailed investigation will be made of:

- Longitudinal dynamics, including the time-of-flight behaviour, the effect of large transverse amplitude particles, the transmission and emittance growth as a function of parameter values, etc.

- Resonances, including emittance growth as a function of acceleration rate and tune variation and the effect of errors.

In addition, much will be learnt from the construction of the first machine of this type.

\section{Lattice}

To prove the principle of NS-FFAGs and investigate the features listed above, EMMA will accelerate electrons from 10 to $20 \mathrm{MeV}$. The parameters of the machine are listed in Table 1. A doublet lattice has been chosen, to minimise cost, and there will be 42 cells. Four cells are shown in detail in Figure 1.

To deliver the aims of the project, 8 different lattice configurations have been designed [6], which probe the longitudinal and transverse dynamics of the machine and 
different regions of the tune diagram. The specifications for EMMA have been determined by these lattices. The main components of the machine are described in following section.

Table 1: EMMA Parameters

\begin{tabular}{|l|l|}
\hline Energy range & 10 to $20 \mathrm{MeV}$ \\
\hline Cell & Doublet \\
\hline Number of cells & 42 \\
\hline RF & 19 cavities; $1.3 \mathrm{GHz}$ \\
\hline Cell length & $394.481 \mathrm{~mm}$ \\
\hline Ring circumference & $16.57 \mathrm{~m}$ \\
\hline
\end{tabular}

The design of the full layout of EMMA is now essentially complete and is shown in Figure 2. EMMA will be built at the STFC Daresbury Laboratory and will use the ALICE accelerator [7] as an injector. ALICE is able to deliver a bunch of sufficient brightness at any energy between 10 and $20 \mathrm{MeV}$, an important criterion for the experimental programme of EMMA.

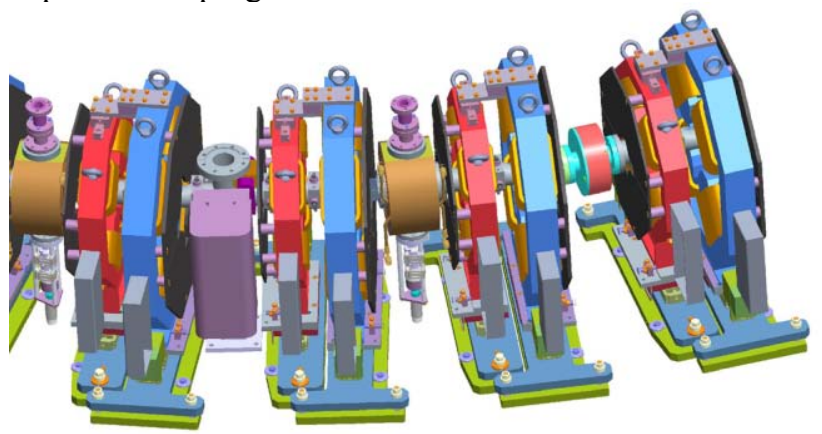

Figure 1: Four EMMA cells, showing the magnets mounted on sliders. Between the middle two cells is an RF cavity. The right gap has a resistive wall monitor and the left an ion pump.

\section{EMMA HARDWARE}

The components of EMMA are at various stages of design and construction. Here, we will discuss only the three main components of the machine: magnets, RF and diagnostics. More detail can be found in other contributions to this conference.

\section{Magnets}

A number of different magnet types are required for EMMA and these are summarised in Table 2. The 84 main ring magnets require independently variable dipole and quadrupole components. They are implemented as quadrupoles and the dipole component is obtained by using them off-axis. This component is adjusted by mounting the magnets on precise, computer controlled sliders. As shown in Figure 1, each doublet is surrounded by clamp plates. These are to prevent field leakage into the iron of the kicker magnets, but are mounted on each doublet to minimise orbit errors from asymmetry. Prototype F and D magnets have been built and measured and the 84 production magnets have been ordered, with delivery due for completion in the autumn.

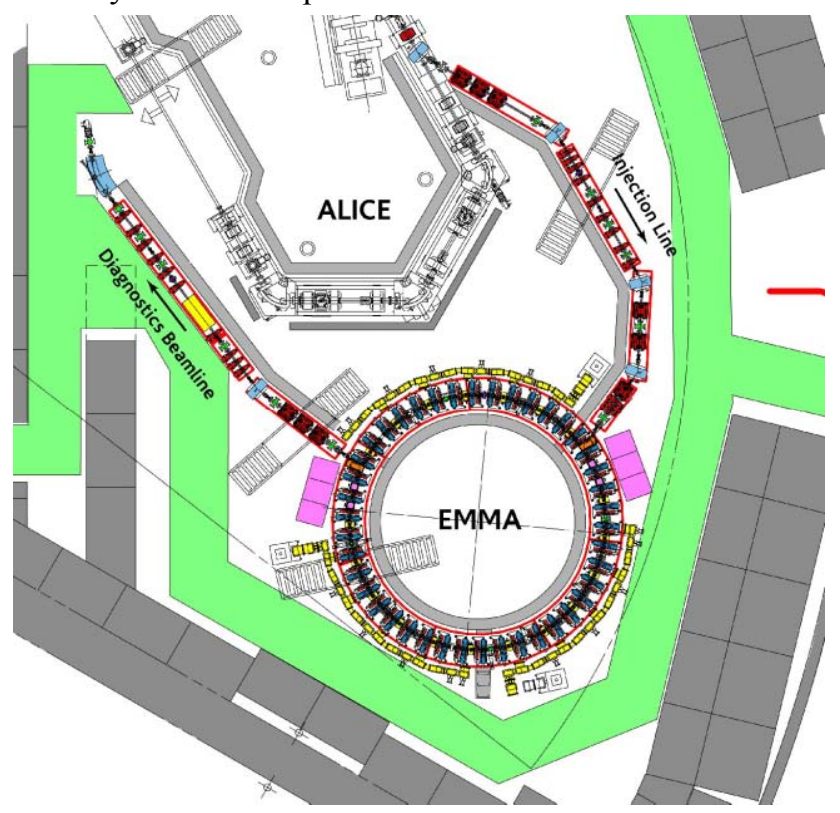

Figure 2: The layout of the complete EMMA complex, including the injector (ALICE), the ring and the injection and extraction lines.

Table 2: EMMA magnets

\begin{tabular}{|l|c|c|}
\hline \multicolumn{1}{|c|}{ LOCATION } & TYPE & NUMBER \\
\hline Injection line & Quad & 18 \\
& Dipole & 4 \\
& V. steerer & 2 \\
\hline Injection system & Septum & 1 \\
& Kicker & 2 \\
\hline EMMA ring & Quad - F & 42 \\
& Quad - D & 42 \\
& V. steerer & $\leq 16$ \\
\hline Extraction system & Septum & 1 \\
& Kicker & 2 \\
\hline Diagnostics line & Quad & 13 \\
& Dipole & 2 \\
& H. \& V. steerers & $?$ \\
\hline
\end{tabular}

The kicker magnets and septa have proved to be the most difficult magnets to design. The selected scheme is to use a septum and two kickers in adjacent cells for both injection and extraction. To avoid passing through the magnets in the neighbouring cell, the entrance and exit angles are $72^{\circ}$. Further, the space available is limited to about $20 \mathrm{~cm}$ for each magnet and the fall (rise) time of the injection (extraction) kicker must be less than the revolution period of $55 \mathrm{~ns}$. To be able to inject and extract and to probe the full acceptance of the ring at all energies, it is also necessary to be able to move and rotate both septa. The designs of the kickers and septa, with their power supplies, are complete and it is expected to go for tender for their construction during June 2008. 
Table 3: The diagnostics requirements of EMMA

\begin{tabular}{|c|c|c|}
\hline Measurement & Device & Number \\
\hline $\begin{array}{c}\text { Beam position } \\
\text { Ring }\end{array}$ & 4 button BPM & 82 \\
\hline $\begin{array}{l}\text { Beam position } \\
\text { Injection }\end{array}$ & $\begin{array}{l}\text { Orthogonal stripline } \\
\text { or button BPM }\end{array}$ & 7 \\
\hline $\begin{array}{c}\text { Beam position } \\
\text { Extraction }\end{array}$ & $\begin{array}{c}\text { Orthogonal stripline } \\
\text { or button BPM }\end{array}$ & 5 \\
\hline $\begin{array}{c}\text { Beam profile } \\
\text { Ring }\end{array}$ & Screens & 2 \\
\hline $\begin{array}{l}\text { Beam profile } \\
\text { Injection }\end{array}$ & Screens & 5 \\
\hline $\begin{array}{l}\text { Beam profile } \\
\text { Extraction }\end{array}$ & Screens & 6 \\
\hline $\begin{array}{c}\text { Beam Profile } \\
\text { Ring }\end{array}$ & Wire scanners & 2 \\
\hline $\begin{array}{c}\text { Beam charge } \\
\text { All }\end{array}$ & Wall current monitor & 3 \\
\hline $\begin{array}{c}\text { Phase wrt RF } \\
\text { All }\end{array}$ & Wall current monitor & 3 \\
\hline $\begin{array}{c}\text { Transmission } \\
\text { All }\end{array}$ & Wall current monitor & 3 \\
\hline $\begin{array}{l}\text { Transmission } \\
\text { Extraction }\end{array}$ & Faraday cup & 1 \\
\hline $\begin{array}{c}\text { Beam loss } \\
\text { Ring }\end{array}$ & Beam loss monitor & 4 \\
\hline $\begin{array}{l}\text { Emittance } \\
\text { Inj/Ext }\end{array}$ & Screens & 3 \\
\hline $\begin{array}{l}\text { Momentum } \\
\text { Ring }\end{array}$ & BPMs and $\mathrm{WCM}$ & \\
\hline $\begin{array}{l}\text { Momentum } \\
\text { Extraction }\end{array}$ & Spectrometer & 1 \\
\hline $\begin{array}{l}\text { Long. Profile } \\
\text { Extraction }\end{array}$ & Electro-optic monitor & 1 \\
\hline
\end{tabular}

Vertical steering magnets are required in both the injection line and the main ring. The former will be used to paint the full vertical acceptance in the ring. Horizontal painting will be performed by the kicker magnets. The vertical steerers in the ring will be used for vertical orbit correction. Space is available for 16 of these, but it is likely that fewer will be required.

\section{RF Cavities}

There will be 19 cavities in EMMA, one every other cell, except for around injection and extraction. They must fit into a slot length of $110 \mathrm{~mm}$ and have an aperture of $40 \mathrm{~mm}$. The maximum gain required per cavity is 120 $\mathrm{kV}$, though up to $180 \mathrm{kV}$ would also be of interest. Considerable effort has gone into modelling the cavities to maximise shunt impedance and minimise the power requirements to deliver this. A prototype cavity has been built by Niowave Inc using this and measurements of its performance have been made. It is shown in Figure 3. The production cavities have been ordered and delivery should be completed in the autumn.
A tender exercise for the complete power system for the 19 cavities has started, with closing date of the end of June 2008.

\section{Diagnostics}

As EMMA is an experimental machine having sufficient diagnostics is crucial. The current requirements and how they will be met are summarised in Table 3 . The diagnostic devices will be mounted in the injection line, to measure the beam properties into EMMA, and in the ring itself. Destructive diagnostics will be mounted in an external extraction line. The machine extraction system has been designed to allow extraction, and hence the use of these devices, at any energy. The table shows the number of devices in each of these locations.

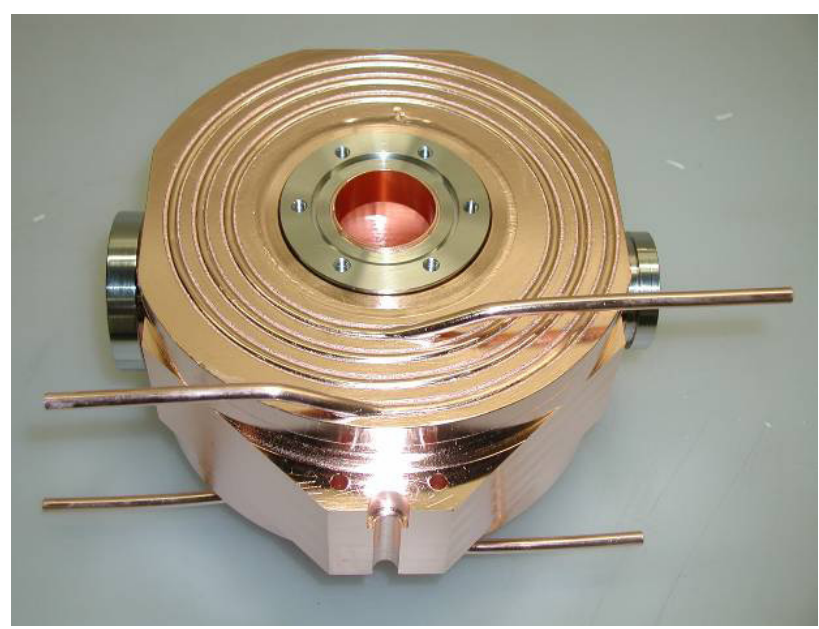

Figure 3: The prototype RF cavity.

\section{REFERENCES}

[1] C. Johnstone et al, Fixed Field Circular Accelerator Designs, PAC'99, New York, March 1999, p. 3068.

[2] K. Long (Ed), An International Scoping Study of a Neutrino Factory and Super-beam Facility, CAREReport-2005-024-BENE, 2005.

[3] C. Johnstone and S. Koscielniak, Longitudinal Dynamics in an FFAG Accelerator under Conditions of Rapid Acceleration and Fixed, High RF, PAC'03, Portland, May 2003, p. 1831.

[4] G.H. Rees, Proton Acceleration - ADS - RIA: 10-MW NS-NL FFAG SNS, FFAG07, Grenoble, April 2007.

[5] E. Keil et al, Hadron Cancer Therapy Complex Employing Non-scaling FFAG Accelerator and Fixed Field Gantry Design, EPAC'06, Edinburgh, July 2006.

[6] J.S.Berg et al, The EMMA Lattice Design, PAC'07, Albuquerque, 2007

[7] S.L.Smith et al, The Status of the Daresbury Energy Recovery Linac Prototype, PAC'07, Albuquerque, 2007 